\title{
News / Nouvelles
}

\section{Amici Thomae Mori}

The International Association of Amici Thomae Mori announces a congress to celebrate the golden jubilee of the canonisation of Thomas More and John Fisher. The International More and Fisher Congress will be held, from July 14 to 21, 1985 at Allen Hall, Chelsea, on the grounds of More's house. The papers, panels and other activities will focus on the thought, writings, lives and martyrdom of the two saints, particularly their Tower works. Persons wishing to submit papers should send a one-page abstract by October 31, 1984, to the North American member of the Program Committee: Dr. Nancy Rutherford Sodeman, 419 Valley Cove Dr., Richardson, TX 75080, Tel. (214) 234-3059; or the organizer of the Congress, Miss Rosemary Rendel, 24, Lennox Gardens, London SW1X ODQ, England, Tel. (1) 584.66.45. For details on the holding of the Congress, write Miss Rendel.

\section{Sixteenth Century Studies Conference}

The Sixteenth Century Studies Conference will meet 24-26 October 1985 in Columbus, Ohio. Proposals for sessions and papers may be submitted to R.B. Waddington, Department of English, University of California, Davis, California 95616. Papers by graduate students and recent Ph.D.s are eligible for the Carl Meyer Prize.

\section{The Mary Stuart Society}

The Society is a nonsectarian group who share an interest in remembering one of the great women of the world. This remarkable female, who by right of birth, inherited the crown of Scotland at a very young age, proves to be a woman for all times. Strong in her convictions and beliefs in the most adverse of historical periods, Mary Queen of Scots displayed a tolerance unparalleled then, and in some cases, even to this day.

While basically functioning as an historical society, the Society would like to further perpetuate the spirit of Mary by support of the arts in all forms. Their social goals in America at present lean toward realization of the Equal Rights Amendment for women and for the renewal and restoration of the recently deemphasized National Endowment For The Arts budget. Membership privileges include full participation in meetings, teas, receptions, openings, lectures, workshops and field trips. For membership consideration contact the Society's secretary, Deanna Rosart-Seaton at: The Mary Stuart Society, 6 St. Lukes Place, New York, N.Y. 10014. 